\title{
Research Article \\ Effect of the Preheating Temperature on Process Time in Friction Stir Welding of Al 6061-T6
}

\author{
Masoud Jabbari \\ Department of Mechanical Engineering, Technical University of Denmark, Nils Koppels Allé, 2800 Kongens Lyngby, Denmark \\ Correspondence should be addressed to Masoud Jabbari; mjab@mek.dtu.dk
}

Received 2 October 2012; Revised 15 April 2013; Accepted 15 April 2013

Academic Editor: Brian Uy

Copyright ( 2013 Masoud Jabbari. This is an open access article distributed under the Creative Commons Attribution License, which permits unrestricted use, distribution, and reproduction in any medium, provided the original work is properly cited.

\begin{abstract}
This paper presents the results obtained and the deductions made from an analytical modeling involving friction stir welding of $\mathrm{Al}$ 6061-T6. A new database was developed to simulate the contact temperature between the tool and the workpiece. A second-order equation is proposed for simulating the temperature in the contact boundary and the thermal history during the plunge phase. The effect of the preheating temperature on the process time was investigated with the proposed model. The results show that an increase of the preheating time leads to a decrease in the process time up to the plunge and the preheating stage. Results of modeling the thermal history showed acceptable agreement with corresponding experimental data from the literature.
\end{abstract}

\section{Introduction}

Friction stir welding (FSW) is a quite innovative process to join metals such as aluminum, magnesium, and steel alloys in the solid state. It was invented by The Welding Institute (TWI) in 1991 [1]. The process consists of a rotating tool which is plunged into two sheets or plates tightly abutted in a line, along which the rotating tool is traversed. During the process, heat is generated by plastic deformation as well as by the friction between the tool and the sample. The sample is eventually joined by the stirring action of the softened (but always solid) material. The advantages of FSW include low residual stress, low energy input, and fine grain size compared to more conventional fusing welding methods. One way to optimize the process is to utilize the thermomechanical modeling of FSW.

A number of academic and industrial institutions have made efforts to develop numerical codes for FSW. Although FSW is simple in concept, the physics behind the process is complex, which includes mechanical heat generation and heat and mass transport. The large strains and strain rates make observing the details of the process difficult, which makes process modeling attractive or essential for understanding it. Colligan [2], Li et al. [3], Guerra et al. [4], and
Schmidt et al. [5] studied the material flow in FSW, which is useful for the investigation of the mechanism of FSW. Xu et al. $[6,7]$ developed a numerical model to capture the main thermomechanical features occurring in the FSW process for the further investigation of the mechanism of FSW.

The microstructure of the friction stir welded 7050-T651 was investigated by Su et al. [8]. Metallurgical, hardness, and quantitative disperse $\mathrm{X}$-ray measurements were performed by Sutton et al. [9] to show that a segregated, banded microstructure consisting of alternating hard particle rich and hard particle poor region is developed in friction stir welding. The superplastic behavior of the welded sections and the one of the base metal were compared by Salem et al. [10]. The feasibility of FSW for joining copper was demonstrated by Lee and Jung [11]. It was shown that the transverse tensile stress reaches about $87 \%$ of that of the base metal, which is slightly higher than that of EBW copper joints. It should be noted that the maximum temperature created by the FSW process ranges from 80 to $90 \%$ of the melting temperature [12, 13], so that welding defects and large distortions commonly associated with fusion welding are minimized or avoided. The heat efficiency in FSW is 95\%, which is higher than that in the traditional fusion welding [14]. FSW contains three stages: plunging, preheating, and traversing. The plunge stage 
in the FSW process is extremely critical since most of the initial thermomechanical conditions are generated and the material undergoes significant transformation due to the high temperatures and stresses involved in the process. The highly dynamic nature of this phase makes it a challenging research area. A thorough understanding of the plunge stage is also important in the development of tools and processes for successfully stir welding of high strength alloys like steel and titanium-based alloys, as most of the tool wear occurs during this phase $[15,16]$. Although there are few experimental studies that focus on the plunge stage $[17,18]$, there are not many numerical models that focus on the thermomechanical conditions developed during the plunge phase. Many of the FEM-based numerical modeling of FSW simulates either the welding stage or the dwell and the welding stages [19-22]. One of the principal difficulties in simulating the plunge stage is the severe mesh distortion of the finite element model which often results in sudden termination of the program. This problem has been successfully dealt with in this research.

A great effort was spent on the analytical models of FSW in order to formulate the heat generation. Russell and Shercliff [23] based the heat generation on a constant friction stress at the tool-matrix interface, equal to the shear yield stress at elevated temperature, which is set to 5 pct of the yield stress at room temperature. The heat input is applied as a point source or line source, and the solution is modified to account for the limited extent of the plate width. Schmidt et al. [19] formulated an analytical model for the heat generation based on different assumptions at the tool-matrix interface. Using this analytical model in comparison with experimental data, the authors suggested that a sticking or close to sticking contact condition is present at the tool/matrix interface. The same authors presented in [24] a new thermal pseudomechanical model where the heat generation is described as a surface flux governed by the material flow stress which in turn depends on the nonuniform temperature at the contact tool matrix interface. In their work, the solution was obtained numerically, and a good correlation with the experimental data was obtained by adjusting only the heat-transfer coefficients' contact resistance. This was the first attempt to develop a thermal model where the total heat generation is not an input parameter but is actually a result of the model itself. Vilaca et al. [25] developed an analytical model for the FSW process, which simulates the asymmetric temperature field developed below the tool shoulder due to the combination of the rotation and linear velocities and hot-to-cold welding conditions. The main limitation of such a model is the need to calculate, for every different welding condition, the thermal input by an iterative procedure, which refers to experimental data. However, it can be considered a good research tool which allowed for the establishment of a systematic relation between the welding parameters and the final mechanical and metallurgical characteristics [26].

In the present study, analytical modeling of the plunge and the preheating stages has been simulated by a newly developed equation. To validate our simulation the results of the thermal history in the plunge section from modeling are compared with the experimental data which were obtained by Hwang et al. [27].

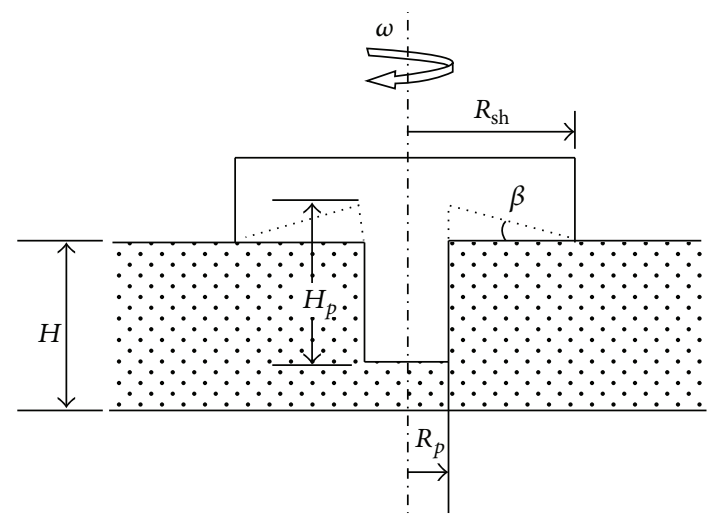

FIGURE 1: Schematic illustration of the tool parameters.

\section{Governing Equation}

The heat flux in FSW is primarily generated by the friction and the deformation process. Thus, the governing equation for heat transfer in FSW is given by (1):

$$
\rho c_{p} \dot{T}+Q_{\text {int }}=\nabla \cdot k \nabla T
$$

where $Q_{\text {int }}$ is the volumetric heat source term arising from plastic dissipation $\left(\mathrm{W} / \mathrm{m}^{3}\right), \rho$ is the density of materials, $c_{p}$ is the mass-specific heat capacity, $k$ is the coefficient of thermal conductivity, $T$ is the temperature, and $\nabla(=i(\partial / \partial x)+j(\partial / \partial y)+$ $k(\partial / \partial z))$ is the gradient operator.

Ferro and Bonollo [28] suggested an equation to calculate the temperature distribution in the workpiece. Their equation was based on thermal analytical modeling, and both thermal and mechanical parameters were used; that is,

$$
\begin{aligned}
T= & T_{0}+\frac{\eta \omega \tau_{0}}{3 k}\left(1-\frac{T^{*}}{T_{M}}\right) \\
& \times\left[\left(R_{\mathrm{sh}}^{3}-R_{p}^{3}\right)(1-\tan \beta)+R_{p}^{3}+3 R_{p}^{2} H_{p}\right] \cdot \Gamma,
\end{aligned}
$$

where $\eta$ is friction coefficient, $\omega$ is rotational speed of the tool, $\Gamma$ is the function of the traverse speed for tool [28], $\tau_{0}$ is tool force, $T^{*}$ is contact temperature, $T_{M}$ is melting point, and the rest are tool parameters which are illustrated in Figure 1.

From this equation, it can be concluded that the contact temperature plays a major role in the determination of the temperature distribution in the whole sample. Hence, in the present work, a second-order equation is proposed for the temperature in the contact boundary relating to process times as well as mechanical parameters. The proposed equation is written as follows:

$$
T^{*}=A+B \cdot t+C \cdot t^{2}
$$

where $T^{*}$ is contact temperature, $A$ is constant and here equal to workpiece initial temperature, $B$ is proportional to $\eta \omega P / k$, and $C$ is proportional to $v / \alpha$. $P$ is a tool force, and $\alpha$ is a thermal diffusivity. Furthermore, $\eta$ is friction coefficient, $\omega$ is rotational speed, $v$ is traverse speed, and $k$ is thermal conductivity. This equation is proposed based on the far-field temperature profiles in the joint welds [24], which 
TABLE 1: Calculated parameters for the proposed model.

\begin{tabular}{ccccccc}
\hline$A$ & $B$ & $C$ & $\eta$ & $\omega(\mathrm{rpm})$ & $P(\mathrm{MPa})$ & $v(\mathrm{~mm} / \mathrm{min})$ \\
\hline 30 & 2.944 & 0.0012 & 0.3 & 920 & 50 & 20 \\
\hline
\end{tabular}

the temperature raise shows almost second-order behavior. The perfect thermal contact is assumed for the simulation, in which the temperature for the tool interface and the work piece are equal in their contact. Calculated constants for the proposed model from the corresponding experimental condition which was conducted by Hwang et al. [27] are listed in Table 1 .

\section{Model Validation}

For numerical modeling, thermal code was developed and written in visual FORTRAN. Workpiece and the contact boundary were discretized by the FDM method. The 3D domain was discretized with relatively fine and structured mesh, and to reduce the computational time, the half of the domain is used in the simulation (by this simplification, the temperature difference in the advancing and the retrieving side of the tool was assumed to be constant). The heat conduction equation for the current simulation was solved by alternating direction implicit (ADI) method, which is most notably used to solve the problem of heat conduction in two or more dimensions and is an example of an operator splitting method. It is assumed that the material properties (i.e., the density and the thermal conductivity) are constant, and they are not depending on the temperature. The dimensions of the workpiece and the tool were read to program on the basis of Hwang et al. [27] experimental set up (see Figure 2). Thermal properties of $\mathrm{Al}$ 6061-T6 were read to the code and initialized the simulation. According to their work [27], the total time for the two stages of plunging and preheating are 83 and 51 seconds, respectively. So the model was set to run for 134 seconds. Results of time temperature for modeling and experimental data in the point near the pin (TC1) are illustrated in Figure 3.

It can be seen that although there are differences between the curves, the trend of the thermal behavior for the modeling and the corresponding experimental data are the same. Maximum deviation between the results occurs around the time 50-100 seconds, where there is transition from stage one (plunge) to the former (preheat). The next reason for the difference is the nature of modeling; there is always intrinsic deviation between results of modeling and experiments. Another reason is the effect of the fact that temperaturedependent parameters are not used in the modeling. Contour of thermal history is shown in Figure 4 with the initial temperature of $30^{\circ} \mathrm{C}$ and after 400 seconds.

\section{Preheating}

For materials with high melting point such as steel and titanium or high conductivity such as copper, the heat produced by friction and stirring may be not sufficient to soften and plasticize the material around the rotating tool. Therefore, it

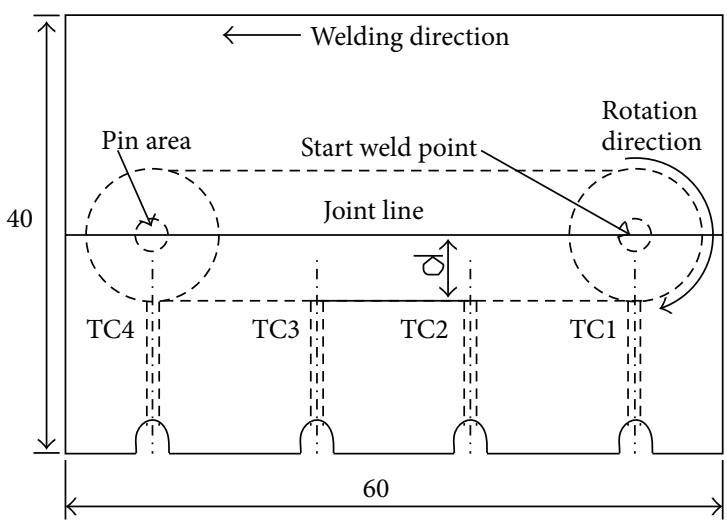

FIGURE 2: Workpiece dimensions and the thermocouple places in the FSW joints [27].

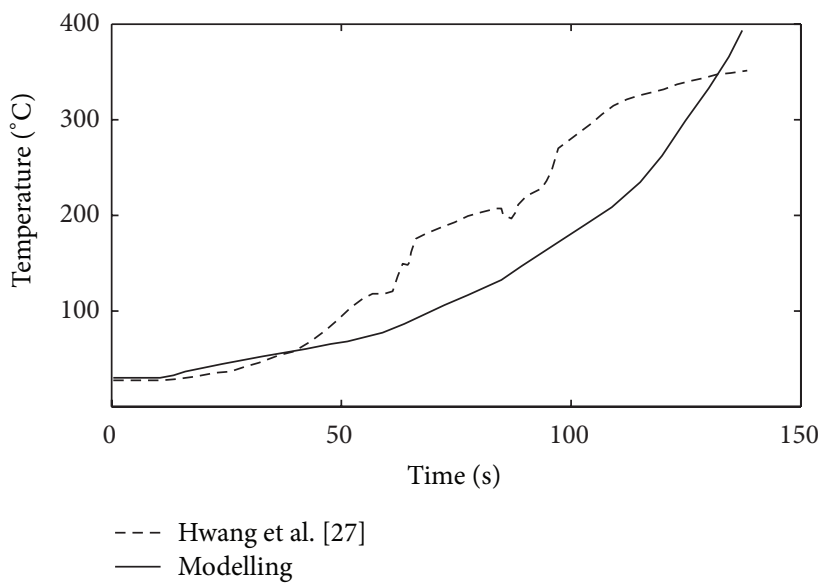

FIGURE 3: Comparison of the modelling and experimental results for the temperature during plunging and preheating.

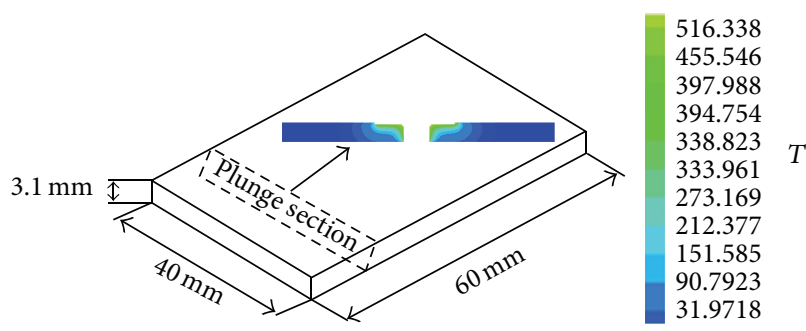

FIGURE 4: Contour of the temperature distribution in the plunging section.

is difficult to produce continuous defect-free welds. In these cases, preheating or additional external heating sources can help the material flow and increase the process window. On the other hand, in materials with lower melting point such as aluminum and magnesium, cooling can be used to reduce extensive growth of recrystallized grains and dissolution of strengthening precipitates in and around the stirred zone.

Preheating of the workpiece before welding should be beneficial for improving welding speed and minimizing tool wear. It may be more simple and practical to preheat the initial plunge region of the workpiece before plunging the pin into the workpiece because the tool wear mainly occurs during 
TABLE 2: Summary of different test cases.

\begin{tabular}{lc}
\hline Test number & Preheating temperature $\left({ }^{\circ} \mathrm{C}\right)$ \\
\hline T1 & 30 \\
T2 & 60 \\
T3 & 120 \\
T4 & 150 \\
T5 & 200 \\
\hline
\end{tabular}

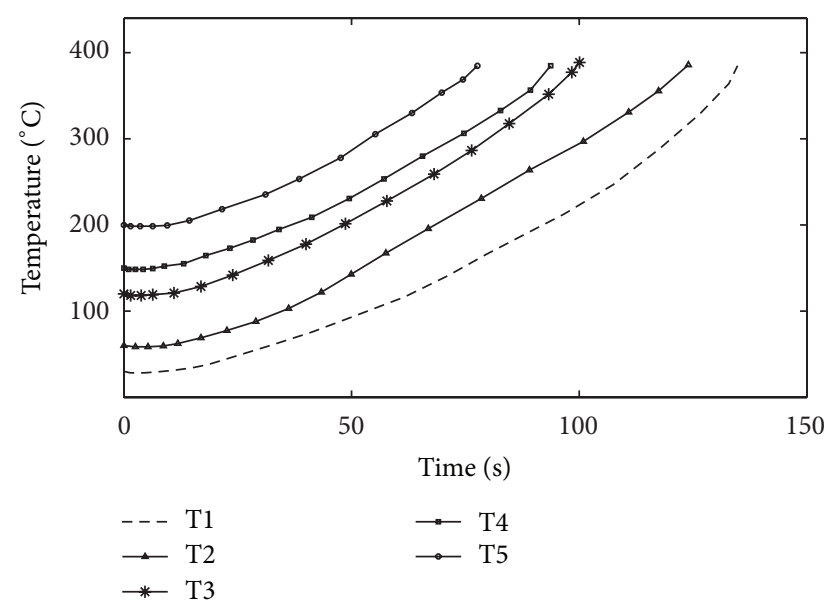

FIGURE 5: Effect of the preheating temperature on the time for reaching the maximum temperature of $384^{\circ} \mathrm{C}$.

the initial plunge period at the start of each weld. Moreover, preheating results in decreasing the process time in FSW. By preheating, the initial temperature for plunge increases, and the tool can easily penetrate the metal.

In the present study, the effect of the preheating temperature on the process time was evaluated using the proposed and validated model from the previous part. Five different cases used for the investigation are listed in Table 2.

In fact, as the preheating temperature increases, the initial temperature in the workpiece is increased. By this fact and our proposed model for contact temperature, five different preheating temperatures were read to the database. By assuming that the maximum temperature at the end of the preheating stage in the FSW process is $384^{\circ} \mathrm{C}$ (according to Hwang et al. experiments [27]), the total time to reach this temperature is evaluated. Results of modeling for five cases are illustrated in Figure 5.

As the preheating temperature increases, the total process time up to the end of the preheating stage is decreased. This results in low-cycle (lower time of the weld) high-quality weld. Moreover, since the temperature of the process in the beginning is high, the deformation of sample becomes easy and voids, and other defects can be avoided. The effect of preheating temperature on process time is illustrated in Figure 6.

From Figure 6, a simple linear behavior for relating preheating time on process time was deducted. This behavior is written as follows:

$$
t_{p}=-0.33 T_{\text {pre }}+143.3
$$

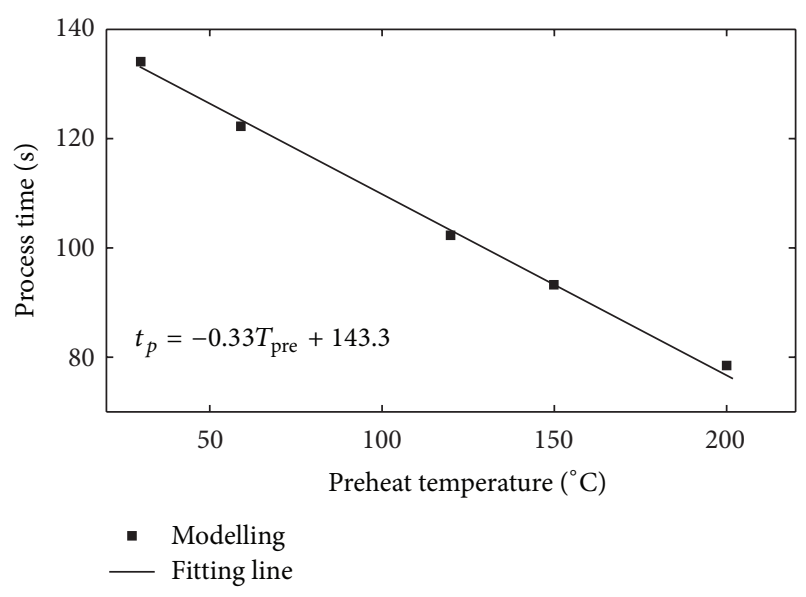

FIGURE 6: Effect of the preheating temperature on the process time.

where $t_{p}$ is the process time and $T_{\text {pre }}$ is the preheating temperature. It should be noted that this equation is valid for the two stages of plunging and preheating.

\section{Conclusion}

An analytical model was developed to simulate the contact temperature in the friction stir welding (FSW). This secondorder equation which contains thermal characteristics and welding parameters was compared and validated by experimental data in the literature. The effect of the preheating temperature on the process time was investigated. The results show that the increase of the preheating temperature not only develops the weld quality, but it also decreases the total process time.

\section{References}

[1] W. M. Thomas, E. D. Nicholas, J. C. Need Ham, M. G. Murch, P. Templesmith, and C. J. Dawes, "Friction Stir Welding," International Patent Application no. PCT/GB92102203 and Great Britain Patent Application no. 9125978.8, 1991.

[2] K. Colligan, "Material flow behavior during friction stir welding of aluminum," Welding Journal, vol. 78, no. 7, pp. 229-237, 1999.

[3] Y. Li, L. E. Murr, and J. C. McClure, "Solid-state flow visualization in the friction-stir welding of $2024 \mathrm{Al}$ to $6061 \mathrm{Al}$," Scripta Materialia, vol. 40, no. 9, pp. 1041-1046, 1999.

[4] M. Guerra, C. Schmidt, J. C. McClure, L. E. Murr, and A. C. Nunes, "Flow patterns during friction stir welding," Materials Characterization, vol. 49, no. 2, pp. 95-101, 2002.

[5] H. N. B. Schmidt, T. L. Dickerson, and J. H. Hattel, "Material flow in butt friction stir welds in AA2024-T3," Acta Materialia, vol. 54, no. 4, pp. 1199-1209, 2006.

[6] S. Xu, X. Deng, A. P. Reynolds, and T. U. Seidel, "Finite element simulation of material flow in friction stir welding," Science and Technology of Welding and Joining, vol. 6, no. 3, pp. 191-193, 2001.

[7] S. W. Xu and X. M. Deng, "A three-dimensional model for the friction stir welding process," in Proceedings of the 21st Southeastern Conference on Theoretical and Applied Mechanics, Orlando, Fla, USA, May 2002. 
[8] J. Q. Su, T. W. Nelson, R. Mishra, and M. Mahoney, "Microstructural investigation of friction stir welded 7050-T651 aluminium," Acta Materialia, vol. 51, no. 3, pp. 713-729, 2003.

[9] M. A. Sutton, B. Yang, A. P. Reynolds, and R. Taylor, "Microstructural studies of friction stir welds in 2024-T3 aluminum," Materials Science and Engineering A, vol. 323, no. 1-2, pp. 160$166,2002$.

[10] H. G. Salem, A. P. Reynolds, and J. S. Lyons, "Microstructure and retention of superplasticity of friction stir welded superplastic 2095 sheet," Scripta Materialia, vol. 46, no. 5, pp. 337-342, 2002.

[11] W. B. Lee and S. B. Jung, "The joint properties of copper by friction stir welding," Materials Letters, vol. 58, no. 6, pp. 10411046, 2004.

[12] W. Tang, X. Guo, J. C. McClure, and L. E. Numes, "Heat input and temperature distribution in friction stir welding," Journal of Materials Processing and Manufacturing Science, vol. 37, no. 2, pp. 163-172, 1998.

[13] P. Colegrove, M. Painter, D. Graham, and T. Miller, "3 dimensional flow and thermal modeling of the friction stir welding process," in Proceedings of the 2nd International Symposium on Friction Stir Welding, Gothenburg, Sweden, June 2000.

[14] Y. J. Chao, X. Qi, and W. Tang, "Heat transfer in friction stir welding-experimental and numerical studies," Journal of Manufacturing Science and Engineering A, vol. 125, no. 1, pp. 138-145, 2003.

[15] W. M. Thomas, "Friction stir welding of ferrous materials: a feasibility study," in Proceedings of the 1st International Symposium on Friction Stir Welding, Thousand Oaks, Calif, USA, 1999.

[16] S. Mandal and K. Williamson, "A thermomechanical hot channel approach for friction stir welding," Journal of Materials Processing Technology, vol. 174, no. 1-3, pp. 190-194, 2006.

[17] M. Santella, "Plunge testing to evaluate tool materials for friction stir welding of $6061+20 \mathrm{wt} \% \mathrm{Al}_{2} \mathrm{O}_{3}$ composite," in Proceedings of the 4th International Friction Stir Symposium, Park City, Utah, USA, 2003.

[18] A. Gerlich, P. Su, G. J. Bendzsak, and T. H. North, "Tool penetration during friction stir spot welding of $\mathrm{Al}$ and $\mathrm{Mg}$ alloys," Journal of Materials Science, vol. 40, no. 24, pp. 64736481, 2005.

[19] H. Schmidt, J. Hattel, and J. Wert, "An analytical model for the heat generation in friction stir welding," Modelling and Simulation in Materials Science and Engineering, vol. 12, no. 1, pp. 143-157, 2004.

[20] H. Schmidt and J. Hattel, "A local model for the thermomechanical conditions in friction stir welding," Modelling and Simulation in Materials Science and Engineering, vol. 13, no. 1, pp. 77-93, 2005.

[21] H. Schmidt and J. Hattel, "Modeling thermomechanical conditions at the tool/matrix interface in Friction Stir Welding," in Proceedings of the 5th International Friction Stir Welding Symposium, Metz, France, 2004.

[22] P. Ulysse, "Three-dimensional modeling of the friction stirwelding process," International Journal of Machine Tools and Manufacture, vol. 42, no. 14, pp. 1549-1557, 2002.

[23] M. J. Russell and H. R. Shercliff, "Analytical modelling of microstructure development in friction stir welding," in Proceedings of the 1st International Symposium on Friction Stir Welding, Thousand Oaks, Calif, USA, 1999.

[24] H. B. Schmidt and J. H. Hattel, "Thermal modelling of friction stir welding," Scripta Materialia, vol. 58, no. 5, pp. 332-337, 2008.
[25] P. Vilaca, L. Quintino, and J. F. dos Santos, "iSTIR—analytical thermal model for friction stir welding," Journal of Materials Processing Technology, vol. 169, pp. 452-465, 2005.

[26] P. Vilaça, L. Quintino, J. F. dos Santos, R. Zettler, and S. Sheikhi, "Quality assessment of friction stir welding joints via an analytical thermal model, iSTIR," Materials Science and Engineering A, vol. 445-446, pp. 501-508, 2007.

[27] Y. M. Hwang, Z. W. Kang, Y. C. Chiou, and H. H. Hsu, "Experimental study on temperature distributions within the workpiece during friction stir welding of aluminum alloys," International Journal of Machine Tools and Manufacture, vol. 48, no. 7-8, pp. 778-787, 2008.

[28] P. Ferro and F. Bonollo, "A semianalytical thermal model for fiction stir welding," Metallurgical and Materials Transactions A, vol. 41, no. 2, pp. 440-449, 2010. 

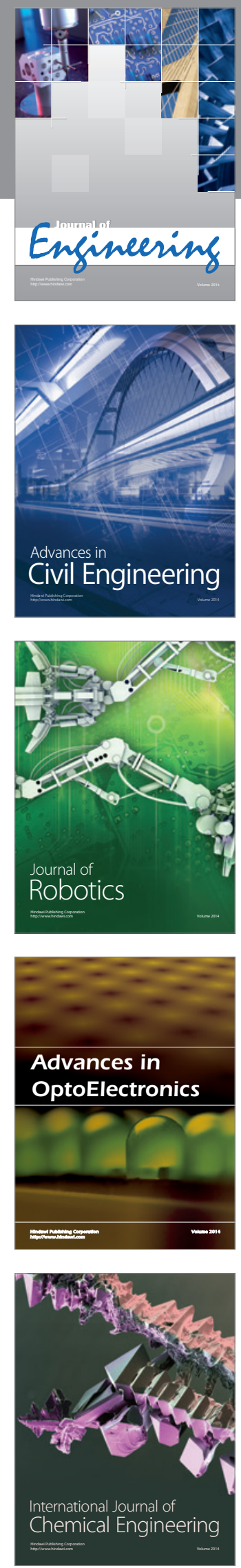

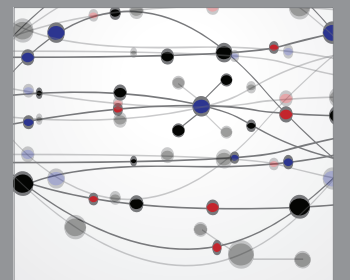

The Scientific World Journal
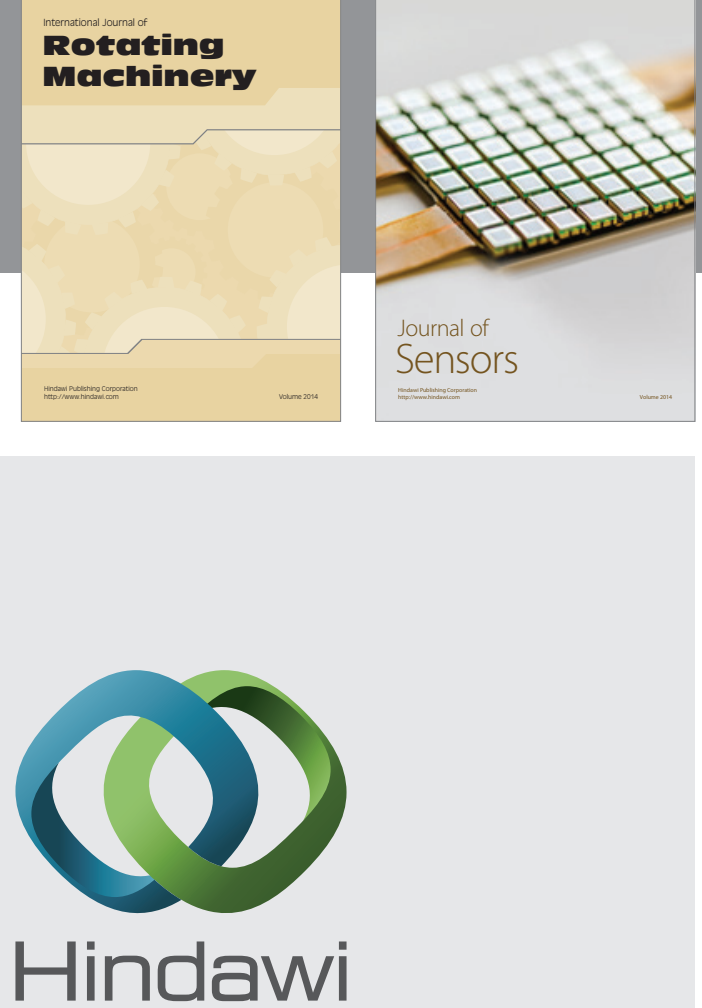

Submit your manuscripts at http://www.hindawi.com
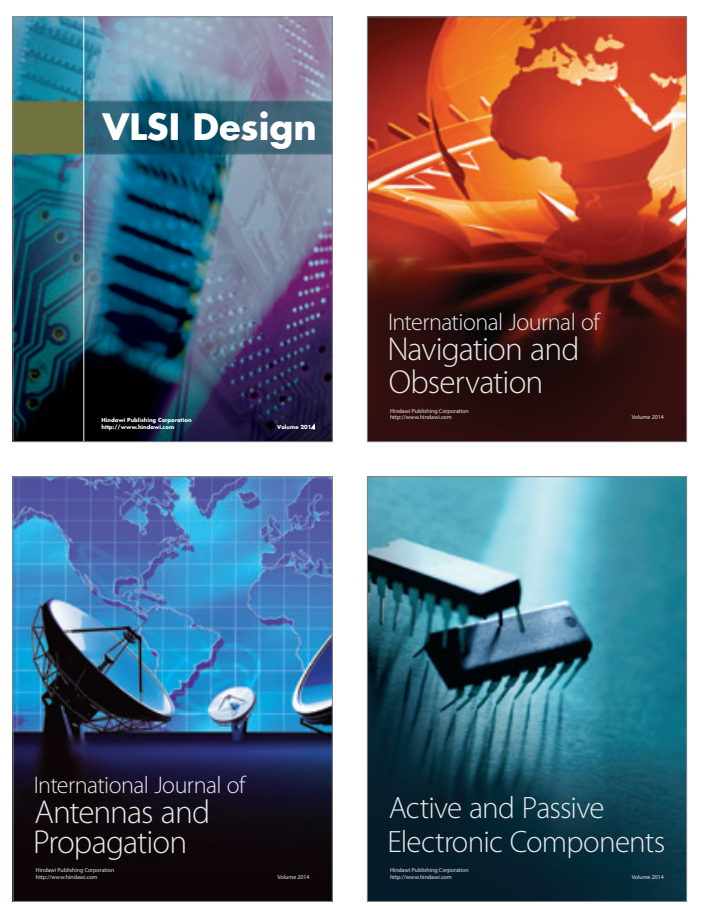
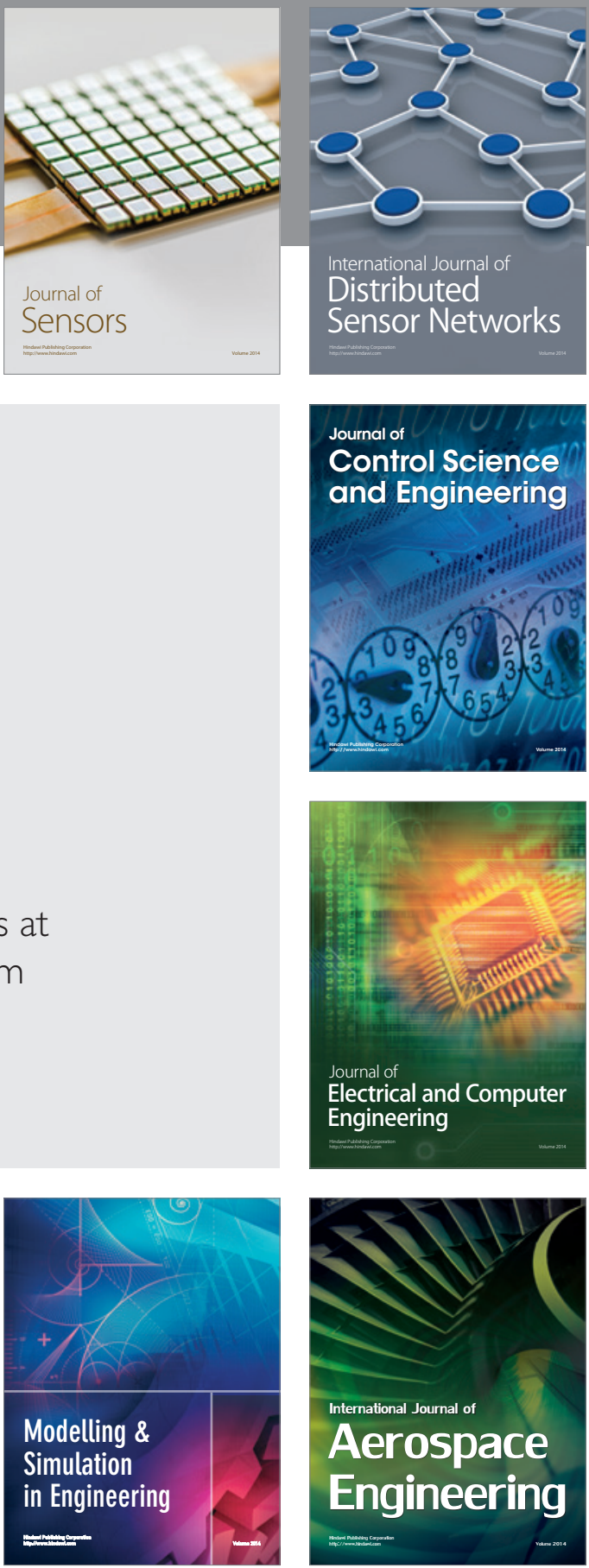

Journal of

Control Science

and Engineering
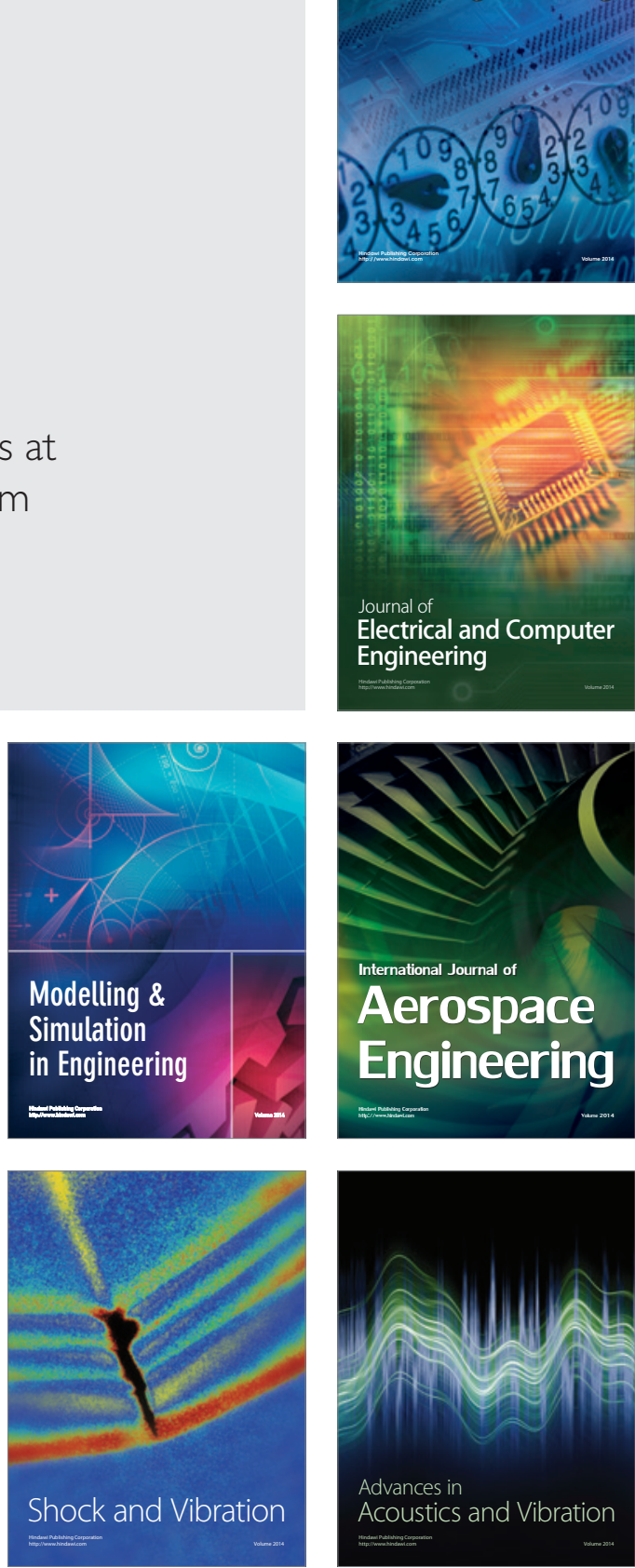